\title{
NEW ENTRY TO 2-AZA-2,4-CYCLOPENTADIENONE BY RING EXPANSION OF 4-AZIDO-2-CYCLOBUTENONE
}

\author{
Masatomi Ohno, ${ }^{\text {ta }}$ Masaru Sekido, ${ }^{a}$ Toru Matsuura, ${ }^{b}$ and Masashi Noda, \\ ${ }^{a}$ Department of Materials Science and Engineering. Toyota Technological Institute, \\ 2-12-1 Hisakata, Tempaku, Nagoya 468-8511, Japan \\ ${ }^{b}$ Department of Molecular Design and Engineering, Graduate School of Engineering, \\ Nagoya University, Chikusa, Nagoya 464-8603, Japan \\ Tel \& Fax +81-587-38-0875: e-mail: onno@toyota-ti.ac.jp
}

\begin{abstract}
Thermal decomposition of 4-azido-3,4-diethoxy-2-phenyl-2-cyclobutenone obtained by phenylation, acetalization and azidation of squaric acid ethyl ester gave rise to a polysubstituted 2-aza-2,4-cyclopentadienone through the combined process of nitrogen extrusion and ring expansion. Anti-aromatic yet resonance-stabilized nature of this product allowed easy isolation and further cyclization with binucleophilic reagents to nitrogen heterocycles.
\end{abstract}

Similar to 2,4-cyclopentadienone, 2-aza-2,4-cyclopentadienone 1 is an intrinsically unstable compound because of an antiaromatic $4 \pi$-electrons system. ${ }^{1}$ Nevertheless, some substituents on the ring enhance stability kinetically and/or thermodynamically to allow handling under isolable conditions. While much less attention has been paid for this aza-analog, the prototype (unsubstituted system) was demonstrated to have the life time of ca. $2 \mathrm{~s}$ at $30^{\circ} \mathrm{C}$ by Gaviña, ${ }^{2}$ and alternatively, stabilized types were reported for some derivatives which are substituted with $t$-butyl, 3 -indolyl, and heteroatom groups. ${ }^{3}$

We have been interested in chemistry of squaric acid 2, especially centering on ring-transformation of its cyclobutenone derivatives triggered by reactive intermediates. ${ }^{4,5}$ Radical, cation, and carbene intermediates generated at the position adjacent to an unsaturated four-membered ring are all possible to initiate ring-expansion reactions to five-membered rings including $2(5 \mathrm{H})$-furanones and cyclopentene-1,3-diones. In these cases, fruitful results were obtained by virtue of effective interaction of the reactive intermediates with the cyclobutenone ring and relief of strain existing in this ring (Scheme 1).

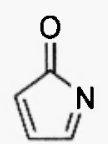

1

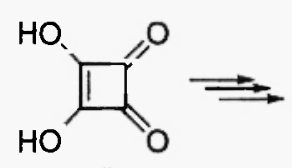

2

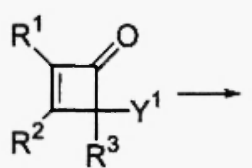<smiles>[R]C1=C([R])C1([R])[Y7]([H])=O</smiles><smiles>[R]C1=[Y](=O)C([R])=C([R])C1=O</smiles><smiles>[R][Y2]1C(=O)C([R])=C([R])C1([R])[Z]</smiles>

$Y^{*}:$ Reactive Intermediate (radical, cation, carbene)

Scheme-1

Along this line, it is reasonable to consider that the nitrene intermediate ${ }^{6}$ induces the analogous pattern of reaction to produce five-membered nitrogen heterocycles; on the basis of a related mechanism (Scheme 1, $Y^{*}=\mathrm{N}$ :), 1,2-acyl shift to the positive nitrene possibly leads to polysubstituted 2-aza-2,4-cyclopentadienones. We now wish to report such a new ring-transformation reaction and utilization of the resulting ring-expansion product.

Azide function was selected as a source of the nitrene intermediate in this experiment. ${ }^{6}$ Introduction of the azide group was carried out by an organosilicon method developed by us. ${ }^{45}$ Thus, substituted cyclobutenedione monoacetals 4 , which were prepared by successive treatment of ethyl squarate 3 with organolithium reagents and ethanol/trifluoroacetic anhydride, ${ }^{7}$ were allowed to react with trimethylsilyl azide under $\mathrm{BF}_{3} \cdot \mathrm{Et}_{2} \mathrm{O}$-catalyzed conditions at $0^{\circ} \mathrm{C}$ for $1 \mathrm{~h}$ (Scheme 2). After usual work-up and purification by silica gel chromatography, 4-azidation products 5 were obtained in good yields. ${ }^{8}$ The structure was confirmed by spectral characteristics showing azide and carbonyl groups ( 2115 and $1765 \mathrm{~cm}^{-1}$ ) in IR, and one 3-ethoxy group and another diastereotopic 4-ethoxy group (dq coupling pattern) in ${ }^{1} \mathrm{H}-\mathrm{NMR}$, and a cyclobutenone ring (requisite three $\mathrm{sp}^{2}$-carbons and one $\mathrm{sp}^{3}$-carbon) in ${ }^{13} \mathrm{C}-\mathrm{NMR}$. ${ }^{9}$ 


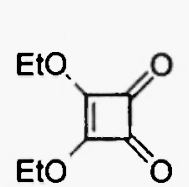

3

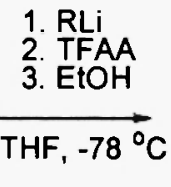

EtO

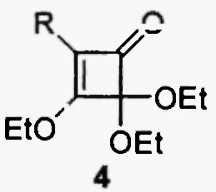

$\frac{\mathrm{TMSN}_{3} / \mathrm{BF}_{3} \cdot \mathrm{Et}_{2} \mathrm{O}}{\mathrm{CH}_{2} \mathrm{Cl}_{2}, 0^{\circ} \mathrm{C}}$

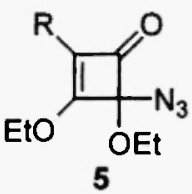

$\mathrm{R}=\mathrm{Ph} \mathrm{Y}: 100 \%$

b $R=$ Me $Y: 89 \%$

c $R=C=-P h \quad Y: 78 \%$

$\mathrm{d} R=\stackrel{\mathrm{CH}=\mathrm{CH}_{2}}{\mathrm{C}} \quad \mathrm{Y}: 68 \%$

Scheme-2

For the next thermal decomposition reaction to generate the aimed nitrene intermediate, the best suited 2-phenyl-substituted case was examined. Thus, 5a was heated in dry p-xylene at reflux temperature under a nitrogen atmosphere, and smooth decomposition was found to occur within $30 \mathrm{~min}$ to give a yellow solution. After direct treatment of the crude product with $\mathrm{H}_{2} \mathrm{O} / \mathrm{NaHCO}_{3}$, maleimide 8 was obtained in $95 \%$ yield. ${ }^{10}$ Similar treatment with ethanol gave acetal $7 \mathbf{b}(R=E t)$ in $79 \%$ yield. Obtained were indeed ring-expansion products following the expected mechanism with the participation of nitrene intermediate 9 . Thus, these results suggest a new entry to 2-aza-2,4-cyclopentadienone by ring expansion of 4-azidocyclobutenone. The scrutinized mechanism may be delineated with two possible routes (Scheme 3): straightforward 1,2-acyl shift to the nitrene center in concertedness $(9 \rightarrow 6)$, or more sophisticatedly, ring-opening of cyclobutenone induced by electron-deficient nature of the nitrene and recombination of the resulting acyl cation and iminyl anion (via 10). "polysubstituted" 2-aza-2,4-cyclopentadienone 6 can survive even at higher temperature. In fact, without addition of water or ethanol, the solution was concentrated and cooled to give 6 itself as yellow crystals (mp 118-119 ${ }^{\circ} \mathrm{C}$ ). The spectral data of isolated 6 was compatible with the expected structure; MS and IR showed the molecular ion peak at m/e 245 and absorptions at 1730 and $1584 \mathrm{~cm}^{-1}$ due to carbonyl and imine groups with no absorption due to an azide group. respectively. Also, ${ }^{1} \mathrm{H}$ NMR showed the required signals due to two ethyl groups one of which was no longer diastereotopic, indicating loss of the chiral center of 4-position, and ${ }^{13} \mathrm{C}$ NMR showed the signals due to ring carbons all of which were $\mathrm{sp}^{2}$-carbons, consistent with the 2-aza-2,4-cyclopentadienone ring. ${ }^{12}$ The enhanced stability of 6 is apparently attributed to double resonance between carbonyl and both ethoxy groups besides phenyl-conjugation.

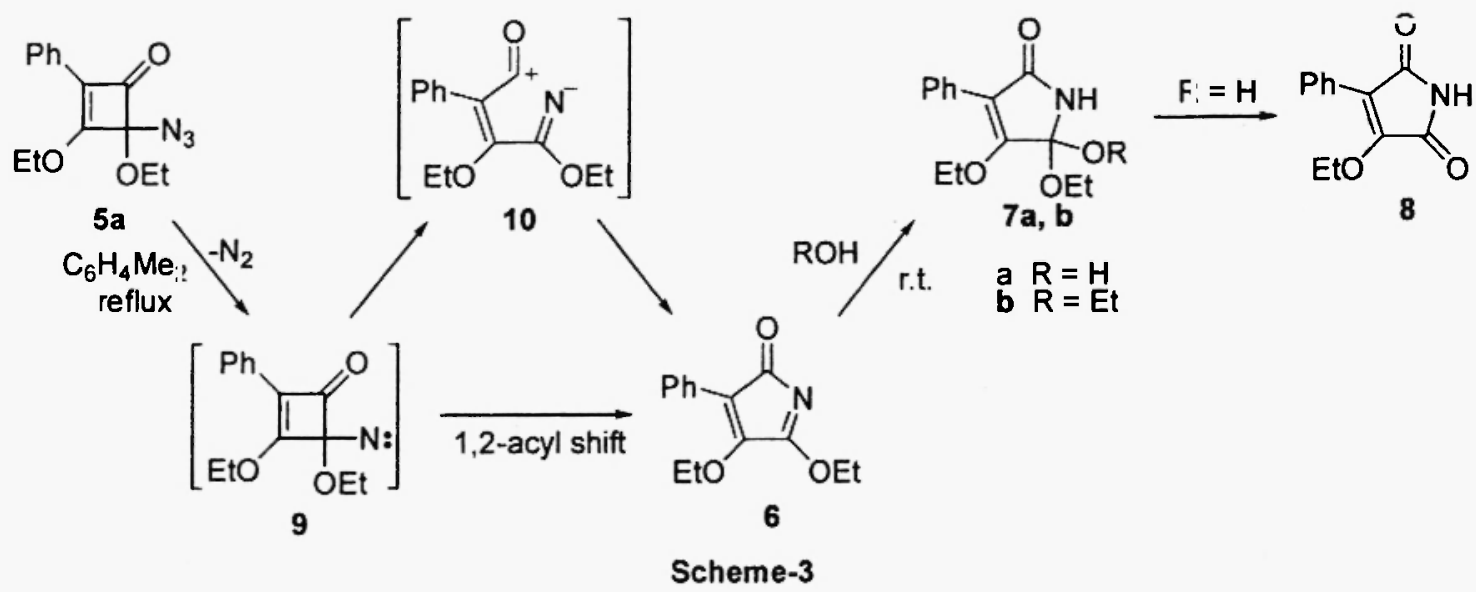

Thus, the polysubstituted 2-aza-2,4-cyclopentadienone 6 is much different in stability from parent 1, yet the LUMO level of 6 is estimated to be considerably low (1: $-1.323 \mathrm{eV}, 6:-1.206 \mathrm{eV}$ by AM1 calculation). Therefore, 6 is anticipated to accept nucleophiles with ease; conveniently, ethoxy groups are feasible in some cases as a leaving group. The reactions with water and ethanol as seen above are informative. Likewise monoamines 11a-d (1.5 equiv.) underwent smooth substitution with crude 6 to give amidines 13 a-d in $71-76 \%$ yields as a result of exo-elimination of ethanol from primary adducts 12a-d (Scheme-4). The excess use (5 equiv.) of a reagent advanced the second substitution at 4-position for the case of $11 \mathrm{~d}$ to give $1: 2$ adduct $14 \mathrm{~d}(\mathbf{4 7 \%})$. This result suggests that heterocyclization is to occur with 
diamines through an intramolecular version. Typically, ethylenediamine 11e was examined. However, the reaction of crude 6 with this binucleophile (1.5 equiv.) gave 1:2 adduct 15e in 35\% yield together with cyclized $18 \mathrm{e}$ in 19\% yield, although 18e was obtainable in $45 \%$ yield by the excess use of $11 \mathrm{e}$ (5 equiv.) to suppress the reaction of primary adduct 13e with another 6 . Yet the same cyclization with excess1,3-propanediamine $11 \mathrm{f}$ resulted in low yield of 18f (12\%) and a similar reaction with ethanolamine $11 \mathrm{~g}$ gave not $18 \mathrm{~g}$ but $13 \mathrm{~g}(81 \%)$ or $14 \mathrm{~g}$ ( $43 \%$ after prolonged time). Chemical behavior in these attempted cyclizations was intuitively unusual, since the second substitution seemed to differ only in an intramolecular process. However, it is essential not to overlook that even substituted 2-aza-2,4-cyclopentadienones preserve antiaromaticity. Equilibration in amidine tautomerism $13 \rightleftarrows 16$ is in effect disfavored; the aimed cyclization necessitates the form of $\mathbf{1 6}$ but it is anti-aromatic. ${ }^{13}$ This forces the cyclization process more or less ineffective. For the problem encountered in this ring system, a reasonable way is to utilize another equilibrium $12 \neq 13$. This permits intramolecular substitution at 4-position prior to exo-elimination (via 17), and thereby the cyclization is no longer interrupted. Actually, appropriate reaction conditions were realized by using ethanol as a solvent. Thus, the crude product $13 \mathrm{f}$ once obtained with $11 \mathrm{f}$ was heated in refluxing ethanol for $12 \mathrm{~h}$ to improve the yield of $18 \mathrm{f}$ to $55 \%$ (based on 5). For the isolated product $13 \mathrm{~g}$ from $11 \mathrm{~g}$, the expected cyclization was performed with the aid of DBU in ethanol (reflux $7 \mathrm{~h}, 74 \%$ yield), but in vain in DMF $\left(90^{\circ} \mathrm{C}, 7 \mathrm{~h}\right)$; this difference rationalized the proposed cyclization mechanism. With these results in hand, binucleophilic anilines $11 \mathrm{~h}-\mathrm{k}$ with $\mathrm{NH}_{2}, \mathrm{OH}, \mathrm{SH}, \mathrm{CH}_{2} \mathrm{OH}$ groups at o-position were subjected to the above established two-step conversion to give tricyclic azaheterocycles $18 \mathrm{~h}-\mathrm{k}$ in $19-76 \%$ yields (based on 5 ). ${ }^{14}$<smiles>[R][R](C)(N)[C@H](C)N</smiles><smiles>[R]NC1(OCC)NC(=O)C(c2ccccc2)=C1OCCO</smiles>

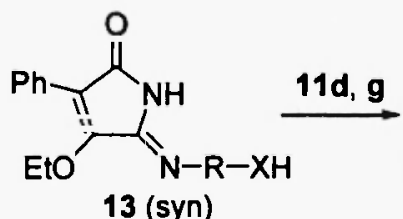<smiles>[R]NC1=C(c2ccccc2)C(=O)NC1=[W]</smiles>

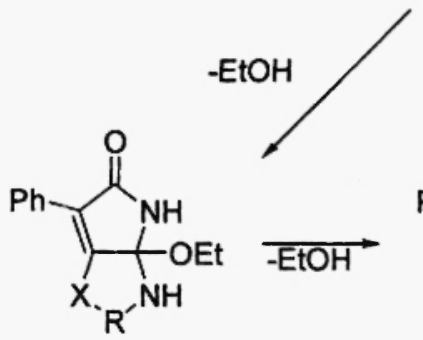

17

$$
\begin{aligned}
& \text { a } X=\text { none, } \mathrm{R}=\mathrm{C}_{6} \mathrm{H}_{4} \\
& \text { b } X=\text { none, } \mathrm{R}=\mathrm{C}_{6} \mathrm{H}_{4} \mathrm{CH}_{2} \\
& \text { c } X=\text { none, } \mathrm{R}=\mathrm{CH}=\mathrm{CHCH}_{2} \\
& \text { d } X=\text { none, } \mathrm{R}=\left(\mathrm{CH}_{2}\right)_{3}
\end{aligned}
$$

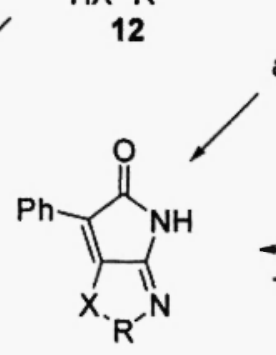
18

$$
\begin{aligned}
& \text { e } X=N H_{1} R=\left(\mathrm{CH}_{2}\right)_{2} \\
& \text { f } X=N H_{1} R=\left(\mathrm{CH}_{2}\right)_{3} \\
& \text { g } X=O, R=\left(\mathrm{CH}_{2}\right)_{2}
\end{aligned}
$$
13 (syn)<smiles>[R]NC1=NC(=O)C(c2ccccc2)=C1OCC</smiles>
16 [e $X=N H, R=\left(\mathrm{CH}_{2}\right)_{2}$ ]<smiles>CCOC1=C(N=C(C)/N=C2\NC(=O)C(c3ccccc3)=C2OCC)C(=O)C(C)=C1c1ccccc1</smiles>

h $\mathrm{X}=\mathrm{NH}$,

i $x=0$,

j $X=S$,

k X $=\mathrm{OCH}_{2}$,

Scheme-4

In summary, ethyl squarate 3 was converted into 4 -azidocyclobutenones 5 by BF $_{3}$-catalyzed azidation of its acetal 4 with $\left(\mathrm{CH}_{3}\right)_{3} \mathrm{SiN}_{3}$, and the 2-phenyl derivative 5a was shown to undergo thermal ring expansion reaction possibly via a nitrene intermediate, giving maleimide after hydrolysis. Owing to resonance-stabilization, the phenyl-substituted 5a was utilized for isolation of polysubstituted 2-aza-2,4-cyclopentadienone 6 and it was applied for further addition reactions. Among them, heterocyclization with binucleophilic reagents was effected by equilibrated conditions in ethanol (to avoid anti-aromatic nature of this ring system). These reactions constitute a new method for heterocycles synthesis based on squaric acid. 


\section{References and Notes}

1. D. L. S. Yokotsuji; W. P. Dailey; A. S. Kende; L. Birzan; K. Liu, J. Phys. Chem. 99, 15870 (1995).

2. a) F. Gaviña; A.M. Costero; M.R. Andreu; M. Carda; S.V. Luis, J. Am. Chem. Soc. 110, 4017 (1988). See also, b) F. Gaviña; A.M. Costero; M.R. Andreu; S.V. Luis, J. Am. Chem. Soc. 110, 6112 (1988). c) F. Gaviña; M. Costero; M.R Andreu; M.D. Ayet, J. Org. Chem. 56, 5417 (1991).

3. a) U. Hees; J. Schneider; O. Wagner; M. Regitz, Synthesis, 835 (1990). b) T. Hoshino; T. Hayashi; T. Odajima J Chem. Soc. Perkin Trans. 1, 1565 (1995). c) A. Schwartz; L.M. Lerner, J. Org. Chem. 39, 21 (1974). d) T. Ito; M Sugimoto; K. Triumi; H. Ito, Chem. Lett. 1477 (1981). e) Y. Ohtsuka, J. Org. Chem. 44, 827 (1979). f) A.M. Bernard; M.T. Cocco; C. Congiu; V. Onnis; P. P. Piras, Heterocycles, 41, 1479 (1995). g) G. H. Elgemeie; A. H. Elghandour; A. M. Elzanate; S. A. Ahmed, J. Chem. Soc. Perkin Trans. 1, 3285 (1997).

4. M. Ohno; S. Eguchi, Directed Synthesis of Biologically Interesting Heterocycles with Squaric Acid (3,4-Dihydroxy3-cyclobutene-1,2-dione) Based Technology in Top. Heterocycl. Chem., 6 "Bioactive Heterocycles I" (Eguchi, S. ed.), Springer-Verlag, Heidelberg, 2006, pp.1-37.

5. M. Ohno; Y. Yamamoto; S. Eguchi, Synlett, 1167 (1998)

6. E. F. V. Scriven, Azides and Nitrenes; Academic Press: Orlando (1984).

7. L. W. Gayo; M. P. Winters; H. W. Moore, J. Org. Chem. 57, 896 (1992).

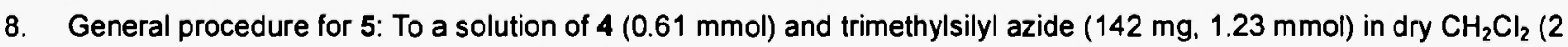
$\mathrm{mL})$, was added $\mathrm{BF}_{3} \cdot \mathrm{Et}_{2} \mathrm{O}(0.093 \mathrm{~mL}, 0.74 \mathrm{mmol})$ dropwise with a syringe at $0{ }^{\circ} \mathrm{C}$ under a nitrogen atmosphere, and the solution was stirred for $1 \mathrm{~h}$. After treating with $10 \%$ aq. $\mathrm{NaHCO}_{3}$ for $10 \mathrm{~min}$, the mixture was extracted with

$\mathrm{Et}_{2} \mathrm{O}(3 \times 10 \mathrm{~mL})$, washed with brine $(10 \mathrm{~mL})$, and dried $\left(\mathrm{Na}_{2} \mathrm{SO}_{4}\right)$. Evaporation of the solvent left the residue, which was chromatographed on a silica gel column (hexane/AcOEt 15/1) to give 5 as oil.

9. NMR data of $5 a\left(C^{2} C_{3}\right):{ }^{1} \mathrm{H}$ NMR $\delta 1.30(3 \mathrm{H}, \mathrm{t}, J=7.0 \mathrm{~Hz}), 1.55(3 \mathrm{H}, \mathrm{t}, J=7.0 \mathrm{~Hz}), 3.86$ and 3.94 (each, $1 \mathrm{H}, \mathrm{dq}, J$ $=9.2,7.0 \mathrm{~Hz}), 4.60(2 \mathrm{H}, \mathrm{q}, J=7.0 \mathrm{~Hz}), 7.28-7.81(5 \mathrm{H}, \mathrm{m}) ;{ }^{3} \mathrm{C}$ NMR $\delta 15.3,15.5,63.4,70.6,104.6,127.7,128.1$, $129.0,129.3,129.8,178.3,185.5$.

10. Patented compound, mp $127.5-129.5^{\circ} \mathrm{C}$ (cf. Umio, S.; Kariyone, K.; Nishida, M. Chem. Abstr. 71, 12859 (1969): observed mp $127.5-129.5^{\circ} \mathrm{C}$.

11. On the other hand, depending on the timing of nitrogen extrusion, it is not ruled out that a 1,2,3-triazepin-7-one ring might be formed advantageously by tandem electrocyclic ring-opening/ring-closure reactions, ${ }^{4.5}$ and this intermediate could undergo ring contraction to 6 with loss of $\mathrm{N}_{2}$.

12. NMR data of $6\left(\mathrm{CDCl}_{3}\right):{ }^{i} \mathrm{H}$ NMR $\delta 1.33(3 \mathrm{H}, \mathrm{t}, J=7.0 \mathrm{~Hz}), 1.52(3 \mathrm{H}, \mathrm{t}, J=7.0 \mathrm{~Hz}), 4.23(2 \mathrm{H}, \mathrm{q}, J=7.0 \mathrm{~Hz}), 4.67(2$ $H, q, J=7.0 \mathrm{~Hz}), 7.31-7.62(5 \mathrm{H}, \mathrm{m}) ;{ }^{13} \mathrm{C}$ NMR $\delta 14.2,15.3,68.5,69.4,114.1,128.50,128.54,129.4,129.9,155.7$, $182.5,183.3$

13. Heat of formation was compared for a case of $R=\operatorname{Pr}(13 d$ and $16 d)$ by $A M 1$ calculation; $13 d$ is slightly more stable $(0.5 \mathrm{kcal} / \mathrm{mol})$ in syn-form (as is depicted in Scheme 4) than in anti-form, and much more stable $(8.5 \mathrm{kcal} / \mathrm{mol})$ than antiaromatic form of $16 \mathrm{~d}$. These results suggest that the syn-form is likely stereochemistry of 13 , and 16 is unlikely tautomer (if not so, the cyclization would have proceeded without difficulty).

14. All of the products $(7,8,13-15,18)$ derived from 6 gave satisfactory spectral data. A typical procedure and spectral data were as follows: A solution of $5 \mathrm{a}(80 \mathrm{mg}, 0.3 \mathrm{mmol})$ in dry p-xylene $(5 \mathrm{~mL})$ was refluxed for 30 min under a nitrogen atmosphere, and the product was cooled and treated directly with $11 \mathrm{e}(0.1 \mathrm{~mL}, 1.5 \mathrm{mmol})$ at room temperature for $1 \mathrm{~h}$. After evaporation of the solvent, the residue was chromatographed on a silica gel column (hexane/AcOEt 5/1) to give $18 \mathrm{e}(30 \mathrm{mg}, 45 \%)$; IR (KBr) $1685,1625 \mathrm{~cm}^{-1} ;{ }^{i} \mathrm{H}$ NMR (DMSO-d $) \delta 3.19(2 \mathrm{H}, \mathrm{dt}, J=6.4$, $2.0 \mathrm{~Hz}), 3.65(2 \mathrm{H}, \mathrm{t}, J=6.4 \mathrm{~Hz}), 7.15-7.78(5 \mathrm{H}, \mathrm{m}), 7.78(1 \mathrm{H}, \mathrm{br} \mathrm{s}), 9.74(1 \mathrm{H}, \mathrm{br} \mathrm{s}) ;{ }^{13} \mathrm{C}$ NMR (DMSO- $\left.d_{6}\right) \delta 38.7$, 45.5, 97.7, 125.6, 127.1, 128.3, 131.8, 138.3, 153.3, 172.2; MS (El) m/e (rel. intensity) 213 ( $\left.\mathrm{M}^{+}, 100\right), 212$ (49), 184 (11), $157(10), 129(10)$

Received on March 16, 2007 